\title{
O DESPERTAR DA CONSCIENTIZAÇÃO AMBIENTAL NO ENSINO DE GEOGRAFIA
}

\author{
Nilza Carvalho da Silva ${ }^{1}$
}

Resumo: Este artigo objetiva apontar como o ensino de geografia pode contribuir para a preservação do meio ambiente, uma vez que, grande parte das problemáticas ambientais, são consequências das relações da sociedade com a natureza. Para o alcance desta temática, desenvolveu-se uma pesquisa bibliográfica direcionada a uma visão fundamentada sobre o meio ambiente e sua preservação no ensino de geografia. Verificando-se assim, que só conseguiremos conscientizar nossos educandos, e transformá-los em cidadãos críticos e responsáveis com a preservação ambiental do mundo em que vivem, se nós professores, buscarmos meios que os direcione a refletir, a partir do seu próprio espaço de ensino.

Palavras-chave: Geografia; Ensino; Meio Ambiente; Conscientização ambiental. 


\section{Introdução}

Nos dias de hoje, a natureza está cada vez mais sendo apropriada e modificada pelo homem, o nosso sistema capitalista que só objetiva o lucro, induz o crescimento de uma sociedade de consumo que vai descartando seus pertences, quando estes não têm mais serventia de uso, em troca de produtos mais avançados, logo, o meio ambiente natural acaba sendo alvo de degradações constantes pelo homem.

Sendo a geografia, uma ciência que dentro da sala de aula, aborda a espacialidade em seu contexto histórico e social, bem como aborda a produção dessa espacialidade através da apropriação e modificação do meio natural pelo homem, para a produção de seu espaço social, é muito relevante que o professor possa ensinar para seus alunos, a importância dos problemas ambientais, uma vez que, estes problemas estão contribuindo para o aquecimento global, mudando assim, a dinâmica climática do nosso planeta.

Nesta perspectiva, verifica-se a importância de abordar a questão do meio ambiente e seus impactos ambientais vivenciados na atualidade, buscando uma conscientização crítica dentro da sala de aula, pois um assunto tão relevante como este, muitas vezes é visto superficialmente na maioria dos livros didáticos durante todo o ano letivo, ocupando assim, os últimos capítulos. Ao lado deste aspecto, nos afirma Andrade (1994), que a geografia tem uma grande contribuição a dar diante da desordem mundial, denunciando, analisando casos, tomando posições. A geografia deve indicar caminhos que defenda uma ordem mais justa, mais humana com uma perspectiva futura a fim de evitar a destruição do próprio planeta como habitat dos seres vivos. Sendo a geografia uma ciência do homem, ela deve ser posta a serviço do homem.

A partir dessas considerações, correlacionar o ensino de geografia com a preservação do meio ambiente, entendendo que o mesmo, pode ser um tema transversal muito importante a ser trabalhado nas aulas de geografia, conseguiremos direcionar o ensino desta ciência na formação de cidadãos mais conscientes e responsáveis com o mundo em que vivem. Partindo desse ponto, precisamos de uma geografia que nos instigue ao conhecimento de nossas ações. (SOUZA, 2010).

Neste sentido, a metodologia da pesquisa é de natureza básica, buscando uma contribuição para o ensino de geografia e o meio ambiente no que se refere à preservação ambiental, visando apenas, um conhecimento intelectual. No que se refere à abordagem do problema, por meio de coleta de dados através de leituras, observação e análise das mesmas, esta pesquisa é qualitativa. Do ponto de vista de seus objetivos, esta é exploratória, pois trabalhou-se com as informações levantadas e selecionadas da literatura exploradas. No que se refere aos seus procedimentos técnicos, por ser pautada na leitura de livros e outras fontes relevantes, esta é bibliográfica. 


\section{O ensino de geografia e a preservação do meio ambiente}

A geografia é uma das poucas disciplinas que está inserida nos Parâmetros Curriculares Nacionais (PCNs), que vai do ensino fundamental ao médio. Neste sentido, ela faz parte e contribui para o desenvolvimento do aluno, o acompanhando em sua vida acadêmica, desde as séries iniciais, a partir do fundamental até o ensino médio. Direcionar o educando a compreensão do espaço ao qual está inserido, assim como, entender as consequências de tais ações na espacialidade, é um dos principais objetivos da geografia escolar. De acordo com Callai (1999, p. 58), "A geografia ao ser estudada deve considerar o aluno na sociedade em que vive. Deve ainda, permitir ao aluno que se perceba como participante do espaço que estuda". Neste sentido, é fundamental que o aluno entenda que as relações sociais existentes, são resultados da vida e do trabalho dos homens, que alguns fenômenos da natureza, interferem diretamente na vida dos homens, assim como, o manuseio inadequado ou inconsciente dos recursos naturais, podem ocasionar consequências desastrosas ao próprio homem.

Conforme Cavalcante (2001, p.24):

Se o espaço contribui para a formação do ser humano este, por sua vez, com sua intervenção com seus gestos, com seu trabalho, com suas atividades, transforma constantemente 0 espaço [...] Portanto, a consciência do espaço, ou a consciência da "geografia" do mundo, deve ser construída no decurso da formação humana, incluindo aí a formação escolar. Nesse sentido 0 ensino de geografia deve visar 0 desenvolvimento da capacidade de apreensão da realidade do ponto de vista da espacialidade.

O professor deve entender que o ensino, é um processo que desperta interesse, assimilação e conhecimento da realidade observada e vivenciada por seus alunos, transformando-os em agentes atuantes e modificadores do espaço, ao mesmo tempo em que os conscientiza que, algumas de suas ações, interferem diretamente no meio, seja este social ou natural.

O ensino é um processo de conhecimento pelo aluno, mediado pelo professor e pela matéria de ensino, no qual devem estar articulados seus componentes fundamentais: objetivos, conteúdos e métodos de ensino. [...] Se se quer ensinar os alunos a pensarem dialeticamente, importa definir ao mesmo tempo, que conteúdos permitam a eles o exercício desse pensamento e o modo sob o qual esse exercício é viável. (CAVALCANTE, 2001, p. 25).

Com base nos aspectos apontados acima, para Cavalcante (2011), o ensino de geografia deve propiciar aos seus alunos a compreensão do espaço geográfico nas suas concretudes e contradições. Portanto trabalhar com a 
problemática ambiental nas aulas de geografia, direciona os alunos a pensarem de forma dialética, pois estes precisam entender que o homem necessita se apropriar e transformar certos recursos naturais, para suprir suas necessidades contemporâneas, mas, ao mesmo tempo em que supre essas necessidades, pode provocar mudanças irreversíveis na natureza o que consequentemente, acaba por agravar ainda mais, os problemas ambientais.

Conforme Anjos (2009, p.13):

O estudo da geografia deve possibilitar aos alunos a compreensão das inter-relações da sociedade com a natureza, como também o entendimento de que as ações individuais ou coletivas trazem consequências tanto para a sociedade quanto para o meio natural. Resultando muitas vezes em consequências irreversíveis para o homem.

A geografia ao ser trabalhada dentro do espaço escolar deve trazer a realidade ao qual o aluno está inserido em todas as esferas, seja econômica, social ou ambiental, e deve mostrar que o homem, é participante e modificador do meio ambiente. Despertar o interesse dos alunos pelas questões ambientais é transformar cidadãos críticos e empenhados com o amanhã. Logo, de acordo com Anjos (2009, p.18):

É fundamental que o professor busque alternativas que facilitem a construção do conhecimento pelo aluno e enriqueçam assim, o processo ensino aprendizagem. Exemplo para isto seria, a fim de promover debates sobre questões atuais e da realidade próxima vivida, abordar os problemas socioambientais e econômicos, como a questão da degradação do meio ambiente, a poluição de rios, a reciclagem do lixo ou as disparidades econômicas e sociais.

Abordar as questões do meio ambiente e seus problemas ambientais dentro da sala de aula, não é torná-lo o assunto mais importante durante todo o ano letivo, mas, tentar encaixá-lo como tema transversal, já é um grande passo para que nós professores, possamos deixar de ser meros reprodutores, e passemos a ser criadores de cidadãos responsáveis e preocupados com 0 mundo em que vivem, desde logo, é importante ressaltar que os próprios Parâmetros Curriculares Nacionais, terceiro e quarto ciclo do ensino fundamental, fazem jus à importância do conhecimento ao meio ambiente, este tem como objetivo para o ensino fundamental, independente da área de ensino um subitem direcionado ao meio ambiente, objetivando para o aluno, "perceber-se integrante, dependente e agente transformador do ambiente, identificando seus elementos e as interações entre eles, contribuindo ativamente para a melhoria do meio ambiente" (BRASIL, 1998, p. 7). 
Já no que se refere ao próprio $\mathrm{PCN}$ de geografia para o ensino fundamental, este tem algumas metas direcionadas ao meio ambiente para que o trabalho pedagógico seja realizado com êxito dentro da sala de aula, Brasil (1998, p.36):

1) Identificar e avaliar as ações dos homens em sociedade e suas consequências em diferentes espaços e tempos, de modo que construam referencias que possibilitem uma participação propositiva e reativa nas questões socioambientais locais.

2) Conhecer o funcionamento da natureza em suas múltiplas relações, de modo que compreendam o papel das sociedades na construção do território, da paisagem e do lugar.

Para que o trabalho pedagógico seja realizado com êxito, nós, professores, devemos dar subsídio aos alunos para que, ao longo da aprendizagem, possamos construir um conjunto de conhecimentos referentes a conceitos, procedimentos e atitudes relacionadas à geografia. (ANJOS, 2009, p.35).

A geografia escolar tem uma grande contribuição a dar diante dos problemas ambientais, somente analisando, conhecendo e direcionando nossos alunos a tomarem uma posição frente a este assunto, é que poderemos indicar caminhos que defenda uma ordem mais justa e mais humana a uma perspectiva futura, a fim de evitar, a destruição do próprio planeta como habitat de seres vivos. (ANDRADE, 1994).

Portanto, precisamos de uma geografia que nos incentive a conhecer nossas ações frente à natureza, para que possamos assim, conhecer o mundo e suas complexidades como potencialidade para construir o espaço de morada que queremos neste planeta redondo de universo infinito. Sendo uma ciência do homem, ela deve ser posta a serviço do homem. (SOUZA, 2010). Neste sentido, só conscientizando nossos alunos, iremos transformar seres humanos preocupados com o nosso espaço de morada.

\section{Aplicação prática dentro da sala de aula}

Desenvolver atividades práticas dentro da sala de aula, é o melhor caminho que o professor pode encontrar, para uma formação crítica e consciente por parte de seus alunos a respeito da preservação do meio ambiente, conforme Filho (2011, p. 17):

Adotando o lema "A começar de mim" que é o olhar para dentro de si e ponto de partida para a formação da consciência ecológica pensar globalmente e agir localmente, aluno por aluno, certamente o educador motivará atitudes eficazes de conservação ambiental. 
Mas que assuntos ligados ao meio ambiente e suas problemáticas ambientais, poderiam ser trabalhados nas aulas de geografia? Pode-se considerar que todos, no entanto, iremos abordar apenas alguns, apontando os motivos porque estes podem ser explorados e aplicados pelo professor dentro da sala de aula. Neste sentido iremos aqui, exemplificar temas como: 1) Aquecimento Global; 2) Escassez de água potável; 3) Desmatamento e queimadas; 4) Poluição do Ar; e 5) Lixo.

No que se refere ao Aquecimento Global - sabemos que sua principal causa é devido à poluição atmosférica, ou seja, atividades humanas propriamente ditas, que lançam na atmosfera gases originários da queima de combustíveis fósseis, intensificando assim o efeito estufa na Terra. Este problema causa enormes consequências como, o aumento significativo da temperatura no planeta, derretimento das calotas polares, além de intensificar alguns fenômenos naturais como furações e ciclones, causando assim, a morte de várias pessoas no mundo.

Ao lado deste aspecto, o professor ao tratar da temática do aquecimento global dentro da sala de aula, deve explicar que tal problema está associado ao desenvolvimento econômico ambicionado pelas civilizações humanas, no entanto, ele também pode ser amenizado por pequenas atitudes como nos aponta Filho (2011), no que se refere à diminuição do aquecimento global no planeta, o ser humano precisa se conscientizar que deve utilizar energias limpas, reciclar, e reaproveitar o lixo, assim como, capturar o gás metano dos aterros sanitários transformando estes, em fonte de energia. Pedir aos seus alunos que pesquisem sobre o aquecimento global, mostra que, mesmo sendo um grave problema enfrentado por nossa geração, este pode ser amenizado através de nossas atitudes.

Escassez e poluição de água potável - abordar este tema é bem interessante, pois mostra aos alunos que nem todas as regiões do mundo possuem água abundante para o consumo doméstico, e que alguns países estão sofrendo diretamente com este problema como: Somália, Etiópia, República Dominicana, Madagascar e até mesmo algumas regiões do Brasil, é o caso do Polígono das Secas, formado por alguns Estados do Nordeste brasileiro como: Alagoas, Ceará, Bahia, Piauí, Pernambuco, Paraíba, Rio Grande do Norte, Sergipe, e a parte norte do Estado de Minas Gerais, estes Estados se localizam em uma área de aridez com índice pluviométrico baixo.

É bom lembrar aos nossos alunos, que nem todas as regiões do nosso país, são privilegiadas por água abundante. Por mais que a maior parte do nosso planeta seja formado por este líquido precioso apenas 2,5\% pode ser consumido, os outros $97,5 \%$ encontra-se nos mares e oceanos. No entanto, o próprio ser humano polui este bem, forçando assim o seu esgotamento. Sabemos que muitos rios são provedores de água potável para o consumo e sobrevivência humana, no entanto, sabemos também que muitos são transformados em verdadeiros esgotos a céu aberto, atitudes desumanas com o próprio meio ambiente natural, ocasionam sérios problemas para o próprio ser humano. 
Neste sentido, direcionar os alunos ao problema da escassez de água potável, assim como, a poluição e desvalorização da mesma é importante para que estes possam entender que nosso líquido precioso, pode acabar pelas próprias atitudes humanas. Para Filho (2011), o educador deve elaborar e cumprir em aula um excelente plano político-pedagógico, capaz de gerar intensa reflexão nos educandos, com a finalidade futura de termos futuros dirigentes compromissados com as questões ambientais.

Desmatamento e queimada das florestas - o desmatamento é um problema histórico no Brasil, este foi proveniente dos portugueses que derrubavam árvores para serem vendidas no mercado europeu como o paubrasil. Esta ação, infelizmente, devastou grande parte da Mata Atlântica. Logo em seguida, foi a vez da floresta Amazônica, que sofreu e sofre com este problema nos dias atuais, embora as políticas que controlem o desmatamento tenham se intensificado nos últimos tempos, mesmo assim, este bioma vem sendo ameaçado tanto por madeireiras ilegais, como também pela intensificação do crescimento urbano. No que se refere às queimadas, estas também são frutos das atividades humanas, que muitas vezes ateiam fogo em áreas verdes para implementar a agricultura e o pasto, no entanto, tal atitude acaba contribuindo para vários problemas no solo, que com o passar do tempo, perde seus nutrientes e vai ficando improdutivo, forçando o desmatamento e a queimada em outras áreas verdes. $O$ aluno deve se conscientizar que muitos recursos que utilizamos vêm das florestas, e que estas, contribuem para a qualidade do ar que respiramos, da água e do solo, logo, estas tem muito mais valor para a humanidade em pé, do que derrubadas.

Poluição do ar - este problema para muitos estudiosos, tem seu agravamento inicial com a revolução industrial no século XVIII, tendo se intensificado a partir do século XIX. Em nome do progresso, do desenvolvimento e do crescimento das nações, todos os anos enormes quantidades de gases poluentes provenientes da queima de combustíveis fósseis, são lançados na atmosfera, gerando enormes consequências negativas para a saúde, para o ecossistema e para patrimônios históricos, no que se refere à saúde, agravam-se as doenças respiratórias como bronquite e asma, além de irritação na pele e ardência nos olhos, no que se refere ao ecossistema, ocasiona a chuva ácida que mata plantas e animais além de comprometer a estrutura de alguns patrimônios históricos localizados em cidades com maior índice de poluição como: Tóquio, Nova lorque, Cidade do México e até mesmo aqui do Brasil como a grande São Paulo.

No entanto, nós professores não devemos só apontar os problemas para nossos alunos, mas também apontar soluções, para Filho (2011), nós seres humanos podemos amenizar tal problema, instalando filtros em todos os elos da cadeia produtiva industrial que pode gerar resíduos para a atmosfera, plantar árvores para sequestrar o carbono, não desmatar, usar bicicleta, andar mais a pé e evitar queimadas. Apontando não só os problemas, mas também soluções, o professor conseguirá atitudes e valores em prol do meio ambiente. 
Lixo - o ser humano é um grande produtor de lixo, pois infelizmente vivemos em uma sociedade consumista, que nos incentiva cada vez mais a ter bens materiais duráveis como carros, eletrodomésticos, máquinas ou equipamentos, e bens não duráveis como: roupas, sapatos, acessórios e alimentos. Produzimos lixo em todos os setores da sociedade, e mesmo os jogando fora, eles continuam existindo e provocando sérias consequências ao meio ambiente e a nós mesmo, pois permanecem intactos nos lixões, durando meses, anos, décadas, e até mesmo muitos séculos como o vidro, que dura até 400 anos para se decompor na natureza. Conforme Filho (2011), quanto mais seres humanos nascem no planeta, maior será a quantidade de lixo produzido, aumentando assim as necessidades de consumo, e o meio ambiente sofre impactos cada vez mais intensos.

Neste sentido, é importante que o professor direcione seus alunos a desenvolver atividades voltadas a reciclagem e ao reaproveitamento dos resíduos sólidos, pois lixo nada mais é do que resíduos sólidos, que mesmo não tendo mais a sua função inicial, pode ter uma ótima função final em nossa casa quando reciclado, podendo ser transformado em objetos úteis e necessários em nosso lar. Ensinando este caminho a nossos alunos contribuímos com formação de pessoas que, embora sendo consumidores, também irão se preocupar com o destino final de seu consumo.

De acordo com Filho (2011, p. 16):

O aluno deve construir o seu conhecimento, e o educando atuar como facilitador para a aquisição deste saber ambiental que, por meio das vivências cotidianas permitirá a mudança de comportamentos nocivos para ações que preservem a natureza.

Com base nos aspectos apontados, explorar temas referentes ao meio ambiente e seus problemas ambientais, dentro da sala de aula, direciona os alunos a pensarem de forma mais consciente no que diz respeito a esta problemática que estamos vivenciando atualmente, fruto de ações inconsciente do próprio ser humano que se apropria do meio natural, modifica este meio, ao mesmo tempo em que o degrada. Logo, o que seria do ser humano sem natureza? Absolutamente não seria nada, desta forma, devemos respeitar a única forma que temos de garantir a nossa sobrevivência na Terra, pois tudo que usamos, utilizamos, vestimos e comemos, provém da mãe natureza.

\section{Conclusões}

No que se refere à temática ambiental, verificamos que esta, está interrelacionada com a geografia, neste sentido, cabe à consciência de cada professor sair um pouco do foco do livro didático, e direcionar também as suas aulas a temas transversais como o meio ambiente e sua problemática ambiental, direcionando seus alunos a problemas existentes tanto em escala local, regional como global. Revbea, São Paulo, V. 10, Nº 1: 75-83, 2015. 
Objetivando a conscientização ambiental dentro da sala de aula, e tratando de um tema tão importante como a preservação do meio ambiente, o professor é sim, capaz de desenvolver nos seus alunos uma consciência mais humana, e de amor no que diz respeito à preservação do nosso planeta Terra, nossa casa, nossa morada e palco de todos os conflitos sociais.

No que se refere ao direcionamento da geografia para a formação de cidadãos mais conscientes e responsáveis com o meio ambiente ao qual estão inseridos, nós professores podemos conseguir essa meta trazendo para dentro da sala de aula, assuntos direcionados a problemática ambiental, colocando não só os pontos negativos, mas também, apontando soluções que amenizem os impactos ocasionados no meio ambiente natural.

A partir dessas considerações, conclui-se neste estudo, que o homem é o principal responsável pela degradação e poluição do meio ambiente, assim como o principal responsável pelo aquecimento global, neste sentido, sendo a geografia uma ciência que correlaciona o homem e o modo como este atua com a natureza, é de fundamental importância que esta ciência, também comece a repensar seus conceitos e conteúdos didáticos direcionando-se a temática ambiental de um modo mais objetivo, pois só assim, conseguiremos transformar nossos alunos em cidadãos conscientes, responsáveis e preocupados com o meio ambiente amanhã. Necessitamos mostrar aos nossos alunos que o ser humano e meio ambiente natural não estão separados, mas sim, integrados em um sistema cíclico, no qual a natureza não precisa do ser humano, mas este jamais poderia existir sem a natureza. Esta conscientização deve ser semeada dentro da sala de aula para que no futuro, sejamos capazes de colher frutos de seres humanos conscientes, de que nada poderão ser, sem o respeito pelo mundo em que vivem.

\section{Referências}

ANDRADE, M.C. Uma geografia para o século XXI. Campinas: Papirus, 1994.

ANJOS, F.A. Currículo de Geografia e os parâmetros curriculares Nacionais. Indial: Grupo Uniasselvi, 2009.

BRASIL. Parâmetros Curriculares Nacionais: geografia. Secretaria de Educação Fundamental. Brasília: MEC/SEF, 1998.

CALLAI, H.C. A formação do Profissional de Geografia. Ijuí: UNIJUÍ, 1999.

CAVALCANTE, L.S. Geografia, Escola e Construção de Conhecimentos. $3^{\circ}$. Ed. São Paulo: Papirus Editora, 2001.

FILHO, P.F. Educando para a Preservação da Vida. Rio de Janeiro: Wak Editora, 2011.

SOUZA, A. Didática e Prática do Ensino de Geografia. Indial: Grupo Uniasselvi, 2010. 